\title{
Ocorrência sincrônica de Carcinoma Espinocelular Bucal Microinvasor e Adenocarcinoma Pulmonar: relato de caso
}

\author{
Synchronous Occurrence of Microinvasive Oral Spin cellular Carcinoma and Pulmonary \\ Adenocarcinoma: case report
}

Ocurrencia sincrónica de Carcinoma Espinocelular Bucal Microinvasor y Adenocarcinoma Pulmonar: relato de caso

Adilson César dos Santos Araújo ${ }^{1 *}$, Arilma Selma de Oliveira Carvalho², Juliana Arôxa Pereira Barbosa $^{3}$, João Carlos de Melo Araújo ${ }^{4}$, André Vasconcelos de Barros Lima ${ }^{5}$, Camila Maria Beder Ribeiro Girish Panjwani ${ }^{6}$.

\section{RESUMO}

Objetivo: abordar o diagnóstico de um Carcinoma Espino Celular Bucal Microinvasor (CECBM) em ocorrência sincrônica com um Adenocarcinoma Pulmonar. Relato de Caso: Trata-se de uma paciente do gênero feminino, 59 anos, que compareceu ao serviço de odontologia do Centro Universitário Cesmac sob queixa de placa branco-avermelhada ulcerada, sem sintomatologia dolorosa que, após anamnese e exames complementares, foi possível diagnosticar Carcinoma Espino Celular Bucal Microinvasor, bem como durante os exames preliminares ao tratamento, foi identificada a presença sincrônica de um adenocarcinoma pulmonar. Considerações finais: lesões de CECBM devem ser diagnosticadas sem subestimar a apresentação clínica e além disso deve-se considerar a ocorrência de segundo tumor maligno primário que nesse caso foi diagnosticado durante a avaliação pré-tratamento oncológico da lesão primária da boca.

Palavras-chave: Carcinoma, Células Escamosas, Diagnóstico, Patologia.

\begin{abstract}
Objective: to approach the diagnosis of a Microinvasive Oral Spino-Cell Carcinoma (CECBM) in a synchronous event with a Pulmonary Adenocarcinoma. Case Report: This is a female patient, 59 years old, who attended the dental service of the Centro Universitário Cesmac, complaining of an ulcerated white-red plaque, with no pain symptomatology that, after anamnesis and complementary examinations, it was possible to diagnose Microinvasive Oral Spino-Cell Carcinoma, as well as during the preliminary examinations of the treatment, the synchronous presence of a pulmonary adenocarcinoma was identified. Final considerations: CECBM lesions should be diagnosed without underestimating the clinical presentation and in addition, the occurrence of the second primary malignant tumor that in this case was diagnosed during the oncological pretreatment evaluation of the primary lesion of the mouth should be considered.
\end{abstract}

Keywords: Carcinoma, Squamous Cell, Diagnosis, Pathology.

\footnotetext{
${ }^{1}$ Centro Universitário Cesmac, Maceió, Alagoas. *E-mail: adilson237@yahoo.com.br

${ }^{2}$ Faculdade de Odontologia da Universidade Federal de Alagoas (FOUFAL), Maceió, Alagoas.

${ }^{3}$ Mestre em Anatomia Patológica. Médica Patologista do HUPAA-UFAL e CEPAMA, Maceió, Alagoas.

${ }^{4}$ Mestre em Anatomia Patológica. Médico Patologista do SVO-UNCISAL e CEPAMA

${ }^{5}$ Cirurgião-dentista da Prefeitura Municipal de Campo Alegre, Maceió, Alagoas.

${ }^{6}$ Universidade Estadual de Campinas (FOP-UNICAMP). Campinas, SP.
} 


\section{RESUMEN}

Objetivo: abordar el diagnóstico de un Carcinoma Espinocelular Bucal Microinvasor (CECBM) en ocurrencia sincrónica con un Adenocarcinoma Pulmonar. Relato de caso: En el presente trabajo se analizaron los resultados obtenidos en el estudio de los resultados obtenidos en el estudio de la enfermedad de Chagas, Carcinoma Espinocelular Bucal Microinvasor, así como durante los exámenes preliminares al tratamiento, se identificó la presencia sincrónica de un adenocarcinoma pulmonar. Consideraciones finales: las lesiones de CECBM deben ser diagnosticadas sin subestimar la presentación clínica y además se debe considerar la ocurrencia de segundo tumor maligno primario que en ese caso fue diagnosticado durante la evaluación pretratamiento oncológico de la lesión primaria de la boca.

Palavras-clave: Carcinoma, Células Escamosas, Diagnóstico, Patología.

\section{INTRODUÇÃO}

O Carcinoma Espinocelular (CEC) é uma das lesões cancerígenas mais frequentes encontradas em cabeça e pescoço, havendo predileção na região de língua e assoalho bucal (VALLE CN, et al., 2016). Comumente está associado a seus principais fatores de risco: o tabagismo e o alcoolismo (VALLE CN, et al., 2016; FERNANDES VS, et al., 2017), mas, também possui uma forte associação com o vírus papiloma humano (HPV 16), com incidência entre a quinta e a sexta década de vida (VALLE CN, et al., 2016; FERNANDES VS, et al., 2017) e predileção pelo sexo masculino (VALLE CN, et al., 2016; SILVA RD e DIAS MAI, 2017).

Ainda assim, taxas de incidência e mortalidade não seguem um padrão e costumam variar bastante de país a país ou mesmo de região para região (BRENER S, et al., 2007).

Apesar do CEC ser diagnosticado com mais prevalência em cavidade bucal, essas taxas acabam sendo influenciadas por hábitos, características socioeconômicas, expectativas de vida, fatores ambientais, raça, nível de educação preventiva e qualidade de assistência médica de determinada região que, por sua vez, precisa fornecer esses dados importantes para estabelecer diretrizes públicas que permitam ações de prevenção e controle do câncer (BRENER S, et al., 2007) e estimar a magnitude dos problemas enfrentados pela população como um todo, facilitando a priorização de ações preventivas e terapêuticas (DOMINGOS PAS, et al., 2014).

De modo geral, sua etiopatogenia é inexata, mas acredita-se que esteja relacionada com a presença de múltiplos fatores de risco carcinogênicos que atuam sobre o epitélio normal que, por sua vez, resultam em uma displasia e na presença de atipias celulares com concomitante perda de estratificação do tecido acometido (GAETTI-JARDIM EC, et al., 2010; COSIN RF, et al., 2016; VALLE CN, et al., 2016; FERNANDES VS, et al., 2017; SILVA RD e DIAS MAI, 2017).

Dentre eles, o fumo - pelos seus compostos conhecidamente carcinogênicos - e o álcool - que eleva o potencial carcinogênico do fumo em 141 vezes - associados ganham destaque, mas ainda estima-se a possibilidade de desenvolvimento do CEC por exposição à radiação, problemas nutricionais, exposição à luz ultravioleta, oncogenes e inibição de supressores de tumor (GAETTI-JARDIM EC, et al., 2010).

Clinicamente, o CEC pode apresentar-se como uma mancha persistente escamosa, vermelha, com bordas irregulares e que sangra com facilidade comumente localizada em face, orelha, nariz, pescoço, dorso de mãos e mucosas oral e genital (SILVA RD e DIAS MAI, 2017).

Especificadamente em mucosa oral, ele apresenta-se como uma lesão exofítica, endofítica ou ainda, como lesões leucoplásicas, eritroplásicas e eritroleucoplásicas associadas ou não a ulcerações de bordas evertidas e endurecidas, indolores e com ausência de halo eritematoso que não cicatrizam em até 15 dias (JOGAIB JC, et al., 2006; GAETTI-JARDIM EC, et al., 2010; VALLE CN, et al., 2016; NEVILLE BW, et al., 2016). 
Radiograficamente, a lesão apresenta destruição óssea subjacente que, quando presente, pode apresentar sintomatologia dolorosa ou ser assintomática. Aparece como uma radiolucidez em "roído de traça" com margens mal definidas ou bordas irregulares de aparência similar à osteomielite, que pode estender-se por vários centímetros ao longo de um nervo sem rompê-lo (JOGAIB JC, et al., 2006; NEVILLE BW, et al., 2016).

De modo geral, a apresentação histopatológica vai depender da localização do CEC. Geralmente ele surge a partir de um epitélio displásico e é caracterizado por ilhas e cordões invasivos de células escamosas epiteliais malignas. Quando biopsiado, está em seu mais precoce momento de invasão e, por isso, termos como "superficialmente invasivo" e "microinvasivo" são empregados (NEVILLE BW, et al., 2016).

Essa invasão é caracterizada pela extensão irregular do epitélio lesional pela membrana basal para o interior do tecido conjuntivo subepitelial que podem estender-se profundamente ao interior do tecido adiposo, músculo e osso subjacentes, destruindo o tecido original à medida da progressão. Geralmente, existe uma resposta inflamatória forte ou imune celular ao epitélio invadido com áreas focais de necrose, o que pode induzir angiogênese e desmoplasia ou alteração cirrótica (NEVILLE BW, et al., 2016).

As células lesionais geralmente mostram um citoplasma eosinofílico abundante com núcleos grandes e hipercromáticos com relação núcleo-citoplasma aumentada. Diferentes graus de pleomorfismo celular e nuclear são observados e pérolas de ceratina podem ser produzidas em seu interior, assim como células isoladas também podem sofrer ceratinização individual (JOGAIB JC, et al., 2006; NEVILLE BW, et al., 2016).

O CEC é classificado de acordo com o seu tecido de origem numa classificação denominada "gradação". As lesões são graduadas em escalas de 3 ou 4 pontos onde as lesões menos diferenciadas recebem os menores números. Assim sendo, tumores que lembram mais seu tecido de origem são menos invasivos do que aqueles anaplásicos ou pobremente diferenciados, tendo um melhor prognóstico (NEVILLE BW, et al., 2016).

Apesar dos esforços relacionados às técnicas de tratamento, o câncer da cavidade oral ainda representa um prognóstico desfavorável com altas taxas de mortalidade (VALLE CN, et al., 2016). Comumente o diagnóstico diferencial acaba por englobar úlcera traumática (GAETTI-JARDIM EC, et al., 2010), leucoplasias, quando em fase inicial sem aumento de volume ou ulceração (NEVILLE et al., 2016), HPV (VALLE CN, et al., 2016; PEREIRA ANV, et al., 2017; PETITO G, et al., 2017; PINTO DA, 2017), paracoccidioidomicose quando em lábio (PERES GL, et al., 2017) e, raramente, tumor de células glanulares (FERREIRA VYN, et al., 2016).

O prognóstico para a sobrevida depende do estadiamento do tumor. Considera-se em $53 \%$ a $68 \%$ dos casos uma taxa relativa de 5 anos para tumores relativamente pequenos $(<4 \mathrm{~cm})$ sem metástase o momento do diagnóstico (estágios I e II); $41 \%$ se maiores sem metástase ou com metástase em um linfonodo ipsilateral menor ou igual a $4 \mathrm{~cm}$ (estágio III); e $27 \%$ se o tumor tiver invadido estruturas adjacentes e metastatizado para um sítio distante ou associado à metástase regional em múltiplos linfonodos ou para um único ipsilateral entre $3 \mathrm{~cm}$ e $6 \mathrm{~cm}$ ou um linfonodo maior que $6 \mathrm{~cm}$ (estágio IV) (NEVILLE BW, et al., 2016).

Diante do exposto, o objetivo do trabalho é relatar a ocorrência sincrônica de dois neoplasmas malignos descobertos em fase inicial e tratados cirurgicamente e discutir os achados com a literatura visto que não foram observados casos semelhantes ao caso em tela.

\section{RELATO DE CASO}

Paciente do gênero feminino, 59 anos, compareceu ao serviço de odontologia do Centro Universitário Cesmac sob queixa de placa branco-avermelhada ulcerada, sem sintomatologia dolorosa. Na anamnese, retratou ser ex-fumante e ex-etilista; apresentou, ao exame extra-oral, linfonodos cervicais de aderências móveis, indolores, de superfície lisa e de consistência macia. No exame intra-bucal, foi constada a lesão em área de rebordo alveolar inferior esquerda com evolução de aproximadamente 1 ano (Figura 1). 
Figura 1 - Exame Clínico Intra-bucal. Lesão do tipo placa brancoavermelhada à distal do dente 34 , evidenciada pelas setas vermelhas.

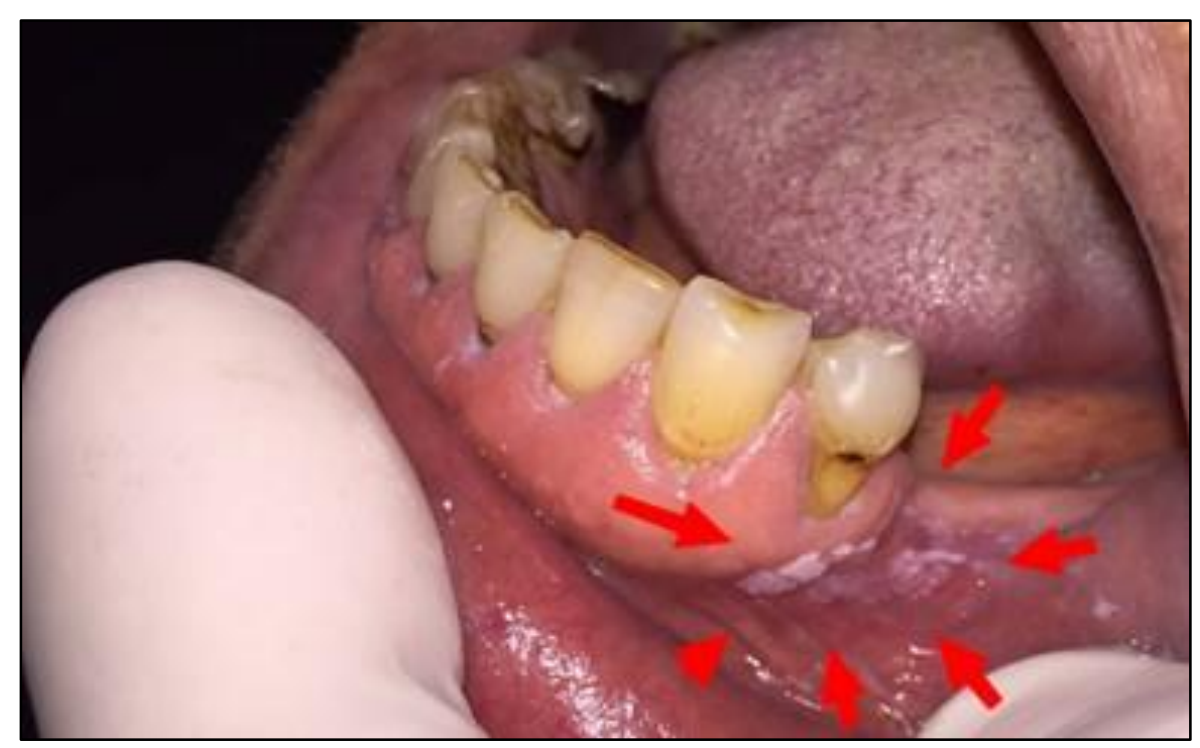

Fonte: Arquivo pessoal, 2018.

Após exclusão de linfadenopatia inflamatória, foi realizada biópsia incisional da lesão bucal. $\mathrm{Na}$ macroscopia do material recebido constava de 4 fragmentos irregulares de tecido, medindo o maior $0,8 \times 0,5 \times 0,4 \mathrm{~cm}$ e o menor $0,7 \times 0,4 \times 0,3 \mathrm{~cm}$. Apresentam coloração castanho-claro e consistência firme-elástica.

Os cortes histológicos da análise microscópica áreas de leucoplasia associada à displasia intraepitelial acentuada e área focal de carcinoma epidermóide microinvasor $(\rightarrow)$. A área da neoplasia apresentou diâmetro de $5 \mathrm{~mm}$ de espessura e $1,5 \mathrm{~mm}$ Nível II de Clark, além de margem cirúrgica periférica livre de neoplasia, distando a menor margem de $5 \mathrm{~mm}$ e margem cirúrgica profunda livre de neoplasia distando $2 \mathrm{~mm}$ (Figuras 2 A e B, e Figura 3 A e B).

Figura 2 - Fotomicroscopia de cortes histológicos mostrando o panorama completo da lâmina histopatológica que revelou áreas de hiperceratose e acantose $(\rightarrow)$ e área central de CECM $(\rightarrow)$ e infiltrado inflamatório crônico (*) (A: em coloração HE 40x; B em coloração HE 100x).

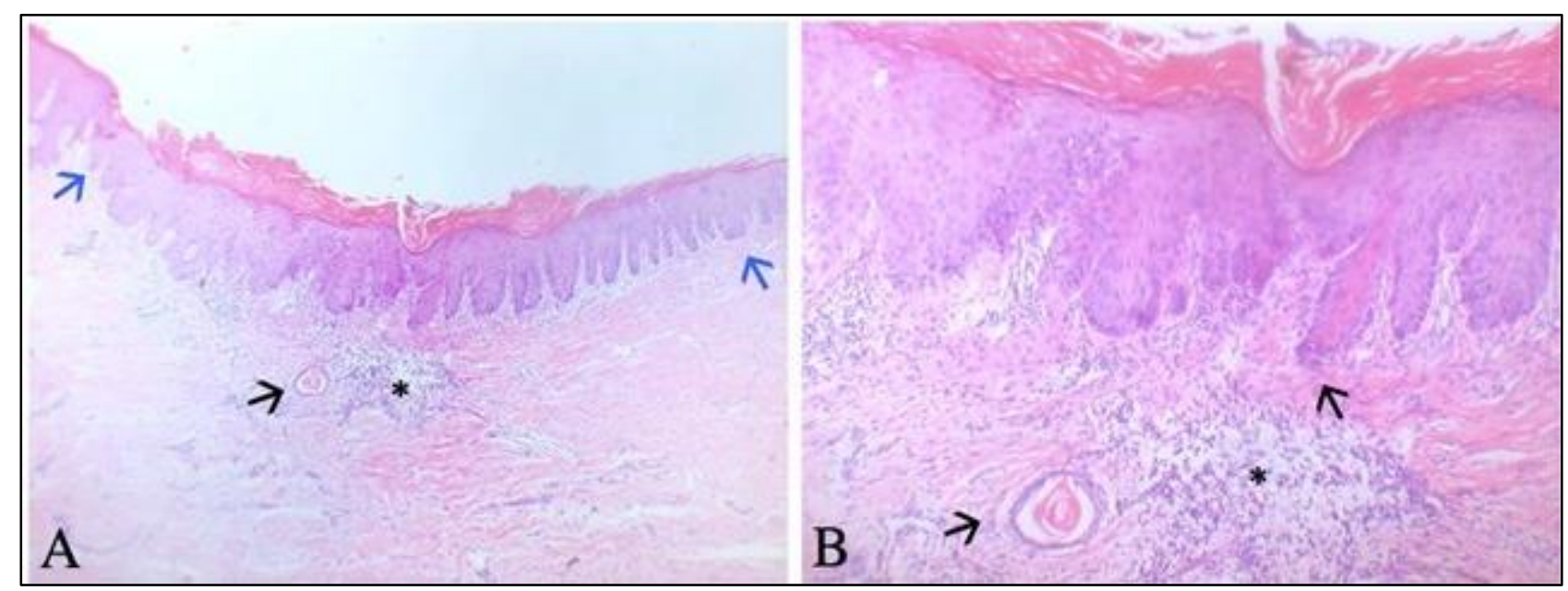

Fonte: Arquivo pessoal, 2018. 
Figura 3 - Fotomicroscopia de cortes histológicos mostrando detalhe da área central de CECM $(\rightarrow)$ e infiltrado inflamatório crônico ( ${ }^{*}$ (A e B: Coloração HE 400x).

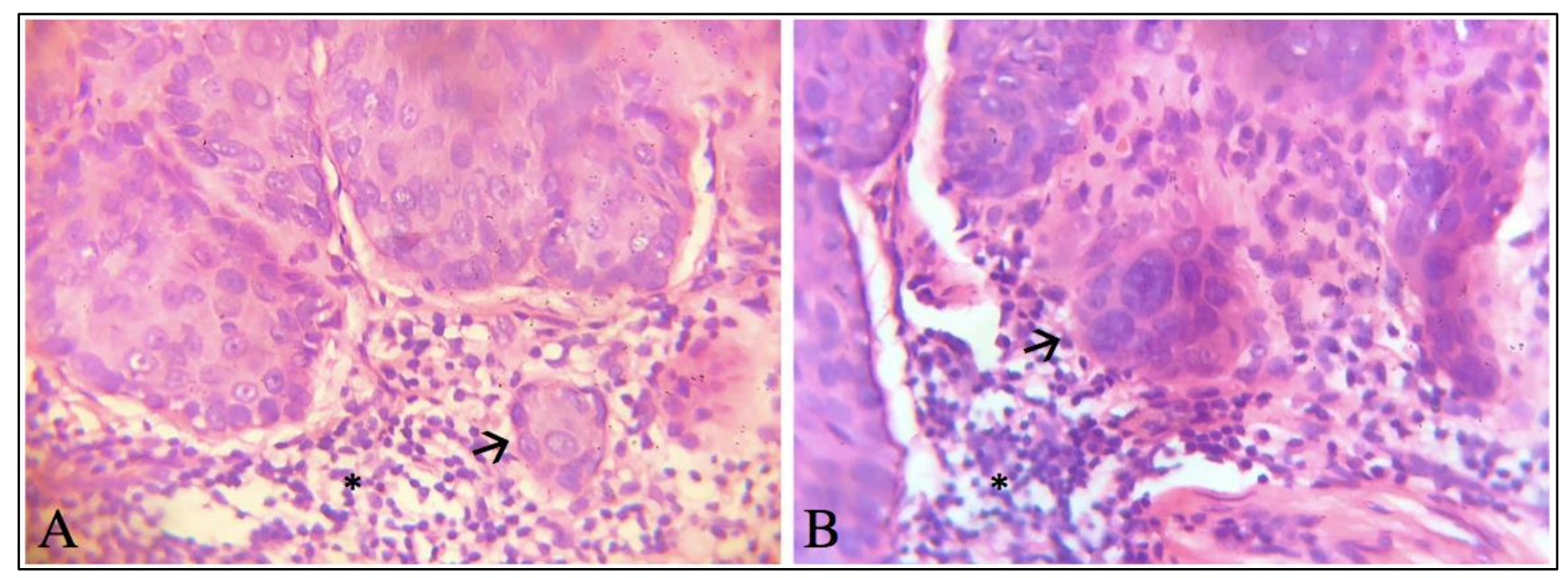

Fonte: Arquivo pessoal, 2018.

Frente este resultado, foram solicitados exames complementares de imagem - radiografias periapicais da área de rebordo alveolar inferior esquerda, radiografia panorâmica, tomografia computadorizada em feixe cônico e reconstrução 3D - foram solicitados para designar a extensão da lesão e nível de comprometimento ósseo (Figuras $4, \mathbf{5}, \mathbf{6}$ ) as quais revelaram que a lesão não comprometia o osso subjacente, corroborando com os achados histopatológicos.

Figura 4 - Radiografias Periapicais da área de rebordo alveolar inferior esquerda. A e B. Periapical da sem alterações da crista óssea.

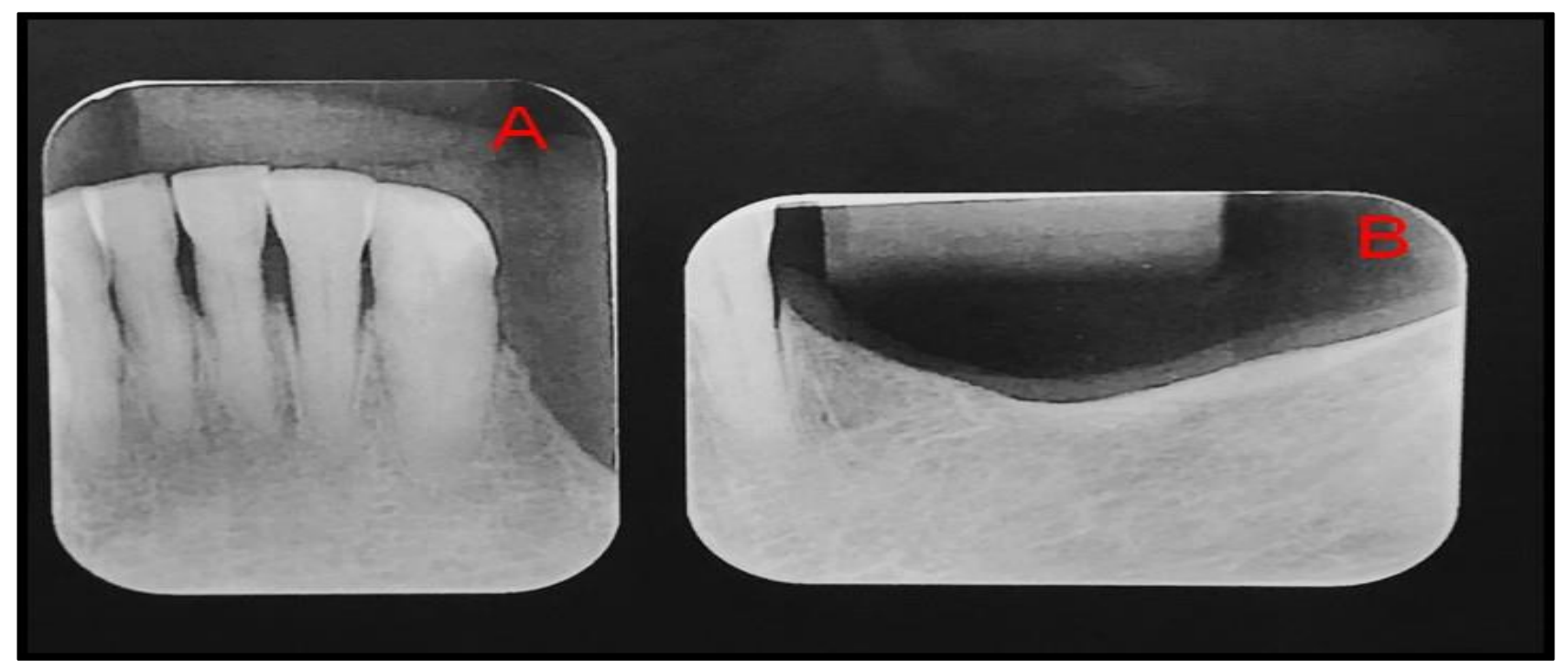

Fonte: Arquivo pessoal, 2018.

Dados os resultados, uma vez constatada uma condição de saúde bucal clínica precária na paciente, houve a necessidade de encaminhá-la para a realização de um condicionamento bucal competente, o que se constituiu de exodontias, raspagem e alisamento corono-radicular e restaurações. Seguido disso, esta recebeu um novo encaminhamento para uma instituição oncológica competente. 
Figura 3 - Radiografia Panorâmica.

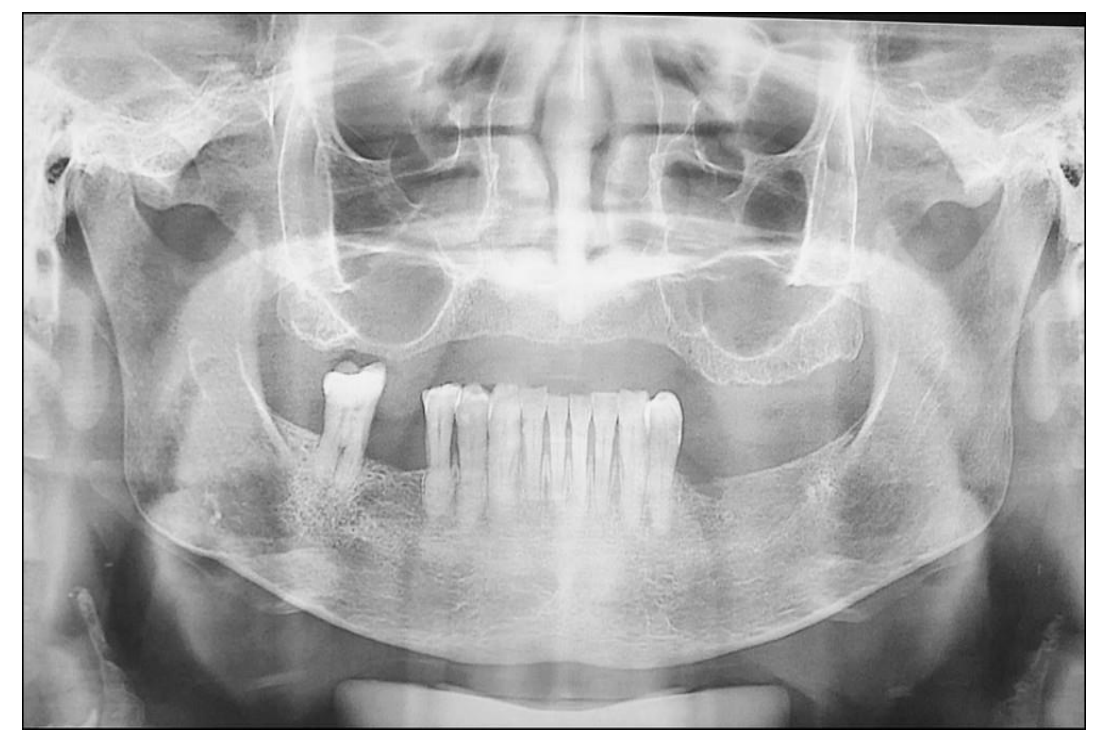

Fonte: Arquivo pessoal, 2018.

A paciente foi encaminhada para tratamento oncológico que foi realizado apenas com exérese cirúrgica da lesão bucal. A qual revelou CEC microinvasor e peça cirúrgica com margens livres de neoplasia.

Entretanto, durante os exames preliminares, foi constatado nódulo pulmonar a partir de radiografia ânteroposterior de tórax e ressonância magnética nuclear. Após realizada uma biópsia por agulha fina, foi diagnosticada com um adenocarcinoma moderadamente diferenciado.

Figura 4 - Tomografia Computadorizada em Feixe Cônico. Corte axial de mandíbula evidenciando alteração em profundidade.

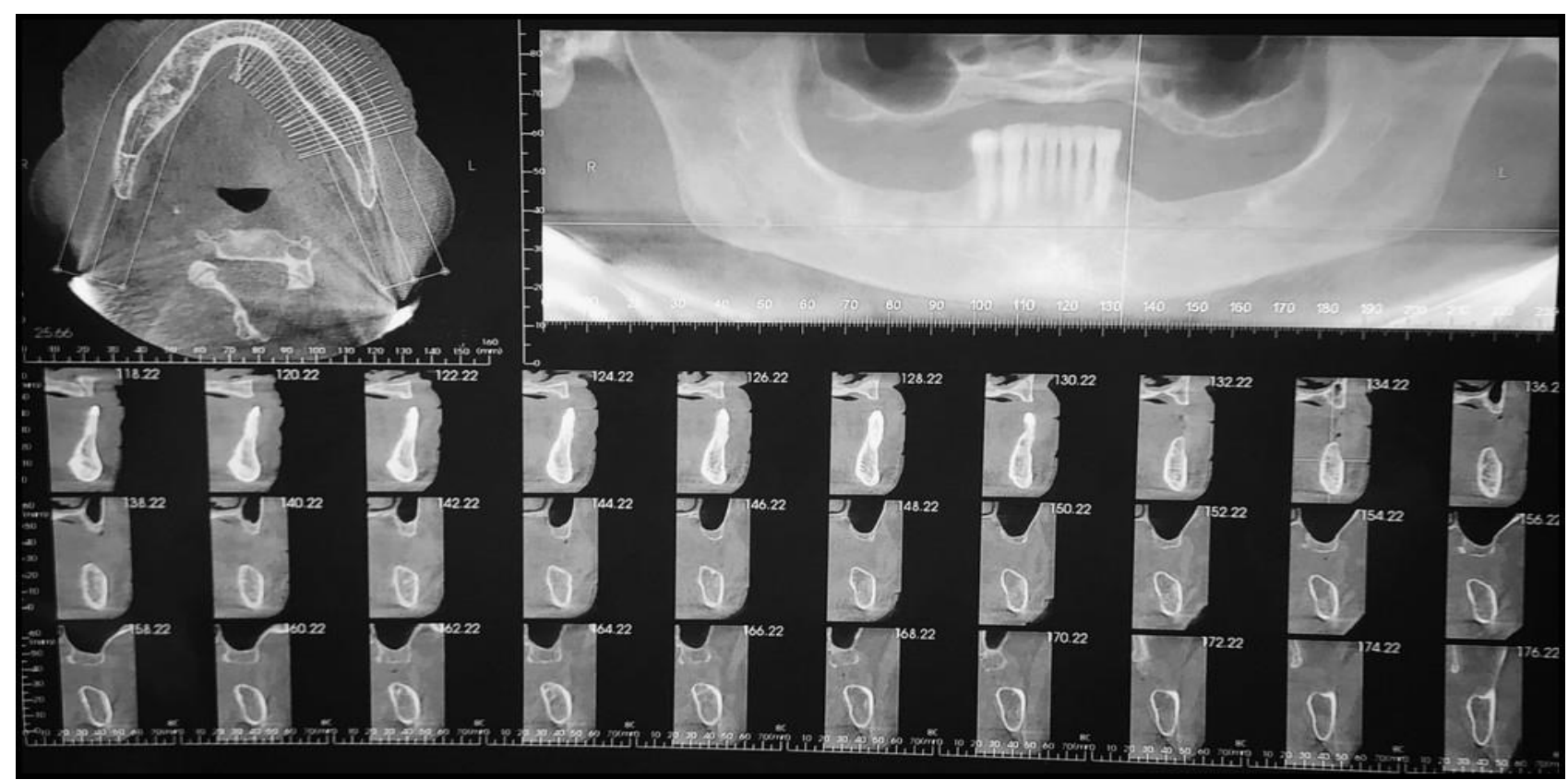

Fonte: Arquivo pessoal, 2018. 
Figura 5: Reconstrução em 3D. Evidenciação de anormalidade em suporte ósseo delimitada pelas setas vermelhas.

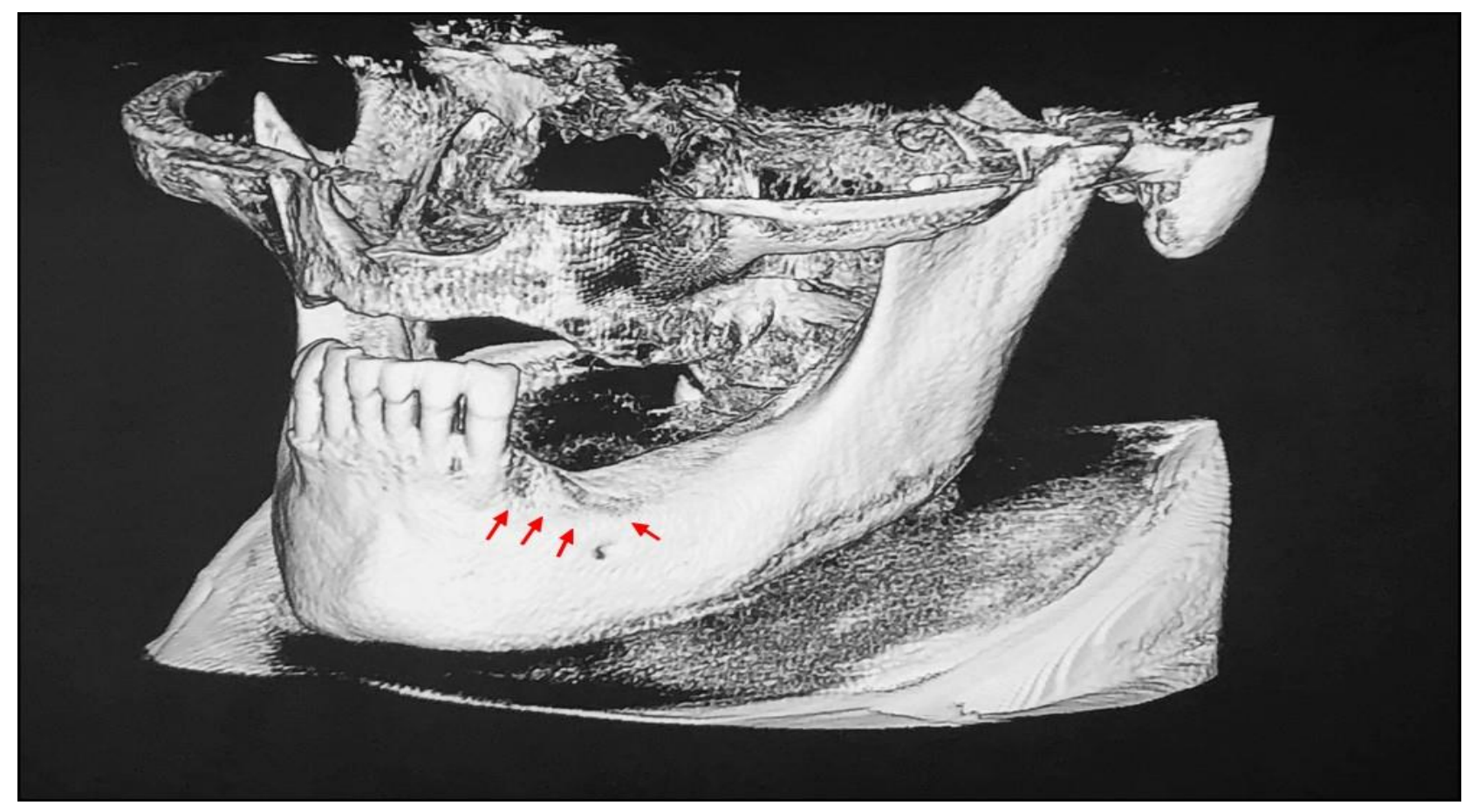

Fonte: Arquivo pessoal, 2018.

Foi realizada uma excisão total da lesão com esvaziamento de linfonodos pulmonares, pelo qual confirmou-se seu diagnóstico com de lesão de adenocarcinoma pouco diferenciado sem metástases linfonodais. Após excisão total do lobo pulmonar afetado, foi concluído o tratamento apenas com cirurgia. Atualmente a paciente encontra-se em acompanhamento estomatológico e oncológico sem sinais de recorrência das duas lesões.

\section{DISCUSSÃO}

No Brasil, são 390 mil casos de câncer de boca e orofaringe são registrados por ano. Destes, 95\% são neoplasias epiteliais do tipo carcinoma de células escamosas ou espinocelular com maior prevalência em raça branca, na faixa etária dos 50 aos 60 anos e gênero masculino (JOGAIB JC, et al., 2006; GAETTIJARDIM EC, et al., 2010; FERNANDES VS, et al., 2017; SILVA RD e DIAS MAI, 2017).

A etiopatogenia do CEC ainda é incerta, mas comumente é associada a múltiplos fatores de risco oncogênicos (JOGAIB JC, et al., 2006; GAETTI-JARDIM EC, et al., 2010; COSIN RF, et al., 2016; NEVILLE BW, et al., 2016; FERNANDES VS, et al., 2017). Embora a literatura defenda uma maior probabilidade de seu desenvolvimento na região de cabeça e pescoço em indivíduos tabagistas e alcoolistas, não se atendo a desistentes do hábito (GAETTI-JARDIM EC, et al., 2010; VALLE CN, et al., 2016; FERNANDES VS, et al., 2017), ainda é comum que também seja associado a fatores ambientais como disparidades sociais, 0 processo de industrialização progressiva no país (FERNANDES VS, et al., 2017), radiação, avitaminoses A, $\mathrm{B}$ e $\mathrm{C}$, deficiência de ferro e a presença de oncogenes, por exemplo (GAETTI-JARDIM EC, et al., 2010).

Geralmente, o fumo e o álcool são comumente eleitos como fatores de risco principais pela sua composição. $O$ tabaco possui compostos carcinogênicos como o alcatrão e a nicotina que, quando associados ao álcool, aumentam a possibilidade de desenvolvimento do CEC em 141 vezes. Mas, por via de regra, por 
si só, o fumo constitui o maior fator de risco para o desenvolvimento de câncer em qualquer idade (GAETTIJARDIM EC, et al., 2010), já que cerca de 90\% dos indivíduos diagnosticados com CEC consomem tabaco sob forma de cigarro, charuto, cachimbo ou mascado (BRENER S, et al., 2007).

Frequentemente esse tipo de tumor possui maior incidência em língua e assoalho bucal, (JOGAIB JC, et al., 2006; GAETTI-JARDIM EC, et al., 2010; COSIN RF, et al., 2016; NEVILLE BW, et al., 2016; FERNANDES VS, et al., 2017; PEREIRA ANV, et al., 2017; SILVA RD e DIAS MAI, 2017) mas, não é incomum que se instale em face, nariz, orelhas, pescoço, dorso de mãos e mucosa genital, uma vez que seja capaz de evoluir de uma lesão de pele preexistente (SILVA RD e DIAS MAI, et al., 2017).

Este caso foi conivente com a literatura ao apresentar histórico de hábitos deletérios do tabaco e do álcool, além da faixa etária esperada. No entanto, nesse caso houve predileção pelo gênero feminino e o CEC acometeu região de rebordo alveolar inferior.

Clinicamente, comumente o CEC é representado pelo rompimento do epitélio e consequente formação de úlcera, com base e consistências endurecidas, sendo incomum a consistência mole e macia (JOGAIB JC, et al., 2006). No presente relato, o clínico mostrou-se semelhante, mas, ainda assim incomum pela presença de placa e consistência, sendo requisitado o exame histopatológico para sua confirmação.

Pereira ANV et al. (2017) apresentaram um caso semelhante onde uma úlcera em borda lateral de língua teve diagnóstico histopatológico de úlcera traumática em primeira instância que, ao longo de 06 meses de evolução, resultou na necessidade de uma segunda biópsia, diagnosticando um caso atípico de CEC, o que o faz um estudo muito interessante ao enfatizar a importância do exame histopatológico e acompanhamento de lesões.

Em relação à apresentação histológica, o CEC se desenvolve a partir da camada de células espinhosas em pele e em mucosas com tendência de ceratinização. Normalmente, quando menor a diferenciação histológica da lâmina, maior é a malignidade da lesão (SILVA RD e DIAS MAI, 2017). Assim, é comum que seja caracterizado por um epitélio displásico com ilhas e cordões invasivos de células escamosas epiteliais malignas em sua composição (NEVILLE BW, et al., 2016).

Apesar dos avanços na área da saúde como um todo, o diagnóstico em estado avançado de lesões malignas é muito comum e, geralmente, resulta em altas taxas de morbidade e mortalidade com sobrevida de até 5 anos (GAETTI-JARDIM EC, et al., 2010; VALLE CN, et al., 2016), variando em decorrência da singularidade individual no que se diz respeito aos hábitos, características socioeconômicas, expectativa de vida, fatores ambientais, raça, educação preventiva e qualidade de assistência médica (PÁDUA TC, et al., 2017).

Por ser de fácil acesso para pacientes, médicos e cirurgiões-dentistas, em tese toda a alteração em cavidade bucal deveria ser perceptível e resultar num diagnóstico precoce. No entanto, isso não acontece muitas vezes devido à falta de conhecimento ou de recursos dos profissionais da área da saúde ou devido ao envolvimento de medo e preconceito por parte dos pacientes, que refletem sua ansiedade no atraso do diagnóstico e, muitas vezes, prejudicam o tratamento e contribuem com um prognóstico desfavorável, o que torna as neoplasias um importante problema de saúde pública (DOMINGOS PAS, et al., 2014; RIBEIRO ILA, et al., 2015).

Quando duas lesões malignas de histologias distintas se desenvolvem em localizações diferentes, elas são consideradas sincrônicas. Esse fenômeno pode ser visto como um efeito colateral do tratamento utilizado para diagnosticar o primeiro tumor ou associado a possíveis fatores de risco como a exposição a carcinógenos no meio ambiente, efeitos da radiação ionizante ou ao uso de modalidades progressivas de tratamento como manipulação hormonal, terapia alvo-induzida, manipulação genética e imunomodulação (ADHJKARI J, et al., 2015; FERRI JVV, et al., 2016). Ainda assim, por via de regra, todo o tratamento eletivo para lesões malignas consiste na remoção de toda a lesão tumoral (VALLE CN, et al., 2016). Na ocorrência de malignidades sincrônicas, torna-se necessário, ainda, investigar o caso e buscar correlações possíveis, uma vez que há

REAS/EJCH | Vol. 11 (12) | e461 | DOI: https://doi.org/10.25248/reas.e461.2019 Página 8 de 9 
maior incidência do acometimento de cânceres num mesmo órgão ou num outro do mesmo sistema se comparados a órgãos sem relação que, na grande maioria dos casos, pode indicar a presença de indícios da possível circulação de metabólitos carcinogênicos (FERRI JVV, et al., 2016).

Nesse caso, duas lesões malignas foram encontradas em estágio inicial e tratadas cirurgicamente no ato da biópsia, devido a conduta satisfatória dos profissionais envolvidos no diagnóstico. O profissional da área da saúde precisa estar atento a todo o tipo de situação. No caso do Cirurgião-Dentista, sendo a boca seu ambiente de trabalho, visando o bem-estar do paciente, é indispensável que exames clínicos e físicos sejam realizados objetivando não só encontrar problemas de origem local como também agravantes de possíveis evoluções e lesões atípicas, sendo necessária sua intervenção e posterior encaminhamento a colegas competentes.

\section{CONSIDERAÇÕES FINAIS}

Diante do exposto conclui-se que é fundamental que as lesões atípicas sejam biopsiadas e observadas a longo prazo, a fim de prevenir ou agir frente a uma situação indesejada de evolução, a depender da predisposição e fatores de risco associados ao paciente. Assim sendo, quanto mais precoce o diagnóstico, melhor o prognóstico que, por sua vez refletirá na qualidade de vida do paciente. Além disso, casos de CECBM devem ser diagnosticados sem subestimar a apresentação clínica e além disso deve-se considerar a ocorrência de segundo tumor maligno primário que nesse caso foi diagnosticado durante a avaliação prétratamento oncológico da lesão primária da boca. Uma vez que a terapêutica esteja fortemente associada ao desenvolvimento da lesão, torna-se imprescindível que o diagnóstico seja realizado o quanto antes a fim de melhorar o prognóstico e, consequentemente, ter um impacto positivo na qualidade de vida do paciente. Assim sendo, esse trabalho tem como intenção estimular a utilização de recursos para o diagnóstico do CEC.

\section{REFERÊNCIAS}

1. ADHJKARI J, et al. Risk of secondary solid malignancies after allogeneic hematopoietic stem cell transplantation and preventive strategies. Future Oncol. 2015; 11(23):3175-85.

2. BRENER S, et al. Carcinoma de células escamosas bucal: uma revisão de literatura entre o perfil do paciente, estadiamento clínico e tratamento proposto. Rev Bras Cancerol. 2007; 53(1): 63-69.

3. COSIN RF, et al. Carcinoma espinocelular de gengiva: aspectos relacionados ao diagnóstico e aderência ao tratamento. Arch Health Invest. 2016; 5(Spec Iss 1): 153.

4. DOMINGOS PAS, et al. Câncer bucal: um problema de saúde pública. Rev. Odontol. Univ. Cid. São Paulo. 2014; 26(1): 4652.

5. FERRI JVV, et al. Malignidades primárias sincrônicas de pulmão e reto: relato de caso e revisão da literatura. Rev Med (São Paulo) 2016; 95(3): 152-155.

6. FERNANDES VS, et al. Recidiva de carcinoma espinocelular de lábio: relato de caso. Arch Health Invest. 2017; 6(Spec Iss 2): 228.

7. FERREIRA VYN, et al. Tumor de células granulares bifocal em mucosa jugal. Rev Cubana Estomatol. $2016 ; 53(3)$ : $162-167$.

8. GAETTI-JARDIM EC, et al. Carcinoma espinocelular: a importância do diagnóstico precoce. Uningá. 2010; 24(1): 1-6.

9. JOGAIB JC, et al. Caso clínico - carcinoma de células escamosas oral. Cad UniFOA. 2006; 1(2): 1-11.

10. NEVILLE BW, et al. Patologia Oral e Maxilofacial. 4.ed. Rio de Janeiro: Elsevier, 2016; 928p.

11. PÁDUA TC, et al. Carcinoma de células escamosas bucal: prevalência no município de Vassouras/RJ entre 2012-2015. Rev Saúde. 2017; 8(1): suplemento 98.

12. PEREIRA ANV, et al. A importância do diagnóstico diferencial entre úlcera traumática e o carcinoma oral de células escamosas. UNIVAG. 2017; 1 (Spec Iss 1): 7.

13. PERES GL, et al. Carcinoma epidermóide em lábio inferior com prognóstico favorável. Arch Health Invest. 2017; 6(Spec Iss 3): 53.

14. PETITO G, et al. Papilomavírus humano (HPV) em carcinomas de cavidade oral e orofaringe na região central do Brasil. Braz J Otorhinolaryngol. 2017 83(1): 38-44

15. PINTO DA. Influência do HPV na saúde oral e a perspectiva da medicina dentária: estado da arte. Dissertação (Mestrado em Medicina Dentária) - Universidade Fernando Pessoa. Faculdade de Ciências da Saúde, Porto, 2017; 26p

16. RIBEIRO ILA, et al. Fatores associados ao câncer de lábio e cavidade oral. Rev. Bras. Epidemiol. 2015; 18(3): 618-629.

17. SILVA RD, DIAS MAI. Incidência do carcinoma basocelular e espinocelular em usuários atendidos em um hospital de câncer. REFACS (online). 2017; 5(2): 228-234.

18. VALLE CN, et al. Carcinoma espinocelular oral: um panorama atual. Rev Patol Tocantins. 2016; 3(4): 82-102. 